\title{
CORRECTION
}

\section{Correction to: The Effects of Acarbose on Non-Diabetic Overweight and Obese Patients: A Meta-Analysis}

\author{
Ai-Qing Yu $\cdot$ Jiong Le $\cdot$ Wen-Tao Huang $\cdot$ Bin Li $\cdot$ Hui-Xin Liang $\cdot$ \\ Qun Wang · Yu-Ting Liu · Charlotte-Aimee Young · Mei-Ying Zhang • \\ Shu-Lan Qin
}

Published online: July 19, 2021

(C) The Author(s) 2021

Correction to: Adv Ther

https://doi.org/10.1007/s12325-020-01602-9

The original article is published with an error in Table 1 . The correct Table 1 is given below.

Open Access. This article is licensed under a Creative Commons Attribution-NonCommercial 4.0 International License, which permits any non-commercial use, sharing, adaptation, distribution and reproduction in any medium or format, as long as you give appropriate credit to the original author(s) and

The original article can be found online at https://doi. org/10.1007/s12325-020-01602-9.

J. Le · W.-T. Huang · H.-X. Liang · S.-L. Qin ( $\varangle)$

Department of Endocrinology, The Fifth Affiliated

Hospital, Southern Medical University, Guangzhou, China

e-mail: 1094821826@qq.com

A.-Q. Yu · B. Li · Q. Wang · Y.-T. Liu

Department of Endocrinology, Third Affiliated

Hospital, Nanchang University, Nanchang, China

M.-Y. Zhang

Department of Endocrinology, Second Affiliated

Hospital, Nanchang University, Nanchang, China

C.-A. Young

Department of Ophthalmology, University of

California, San Francisco, CA, USA the source, provide a link to the Creative Commons licence, and indicate if changes were made. The images or other third party material in this article are included in the article's Creative Commons licence, unless indicated otherwise in a credit line to the material. If material is not included in the article's Creative Commons licence and your intended use is not permitted by statutory regulation or exceeds the permitted use, you will need to obtain permission directly from the copyright holder. To view a copy of this licence, visit http:// creativecommons.org/licenses/by-nc/4.0/. 


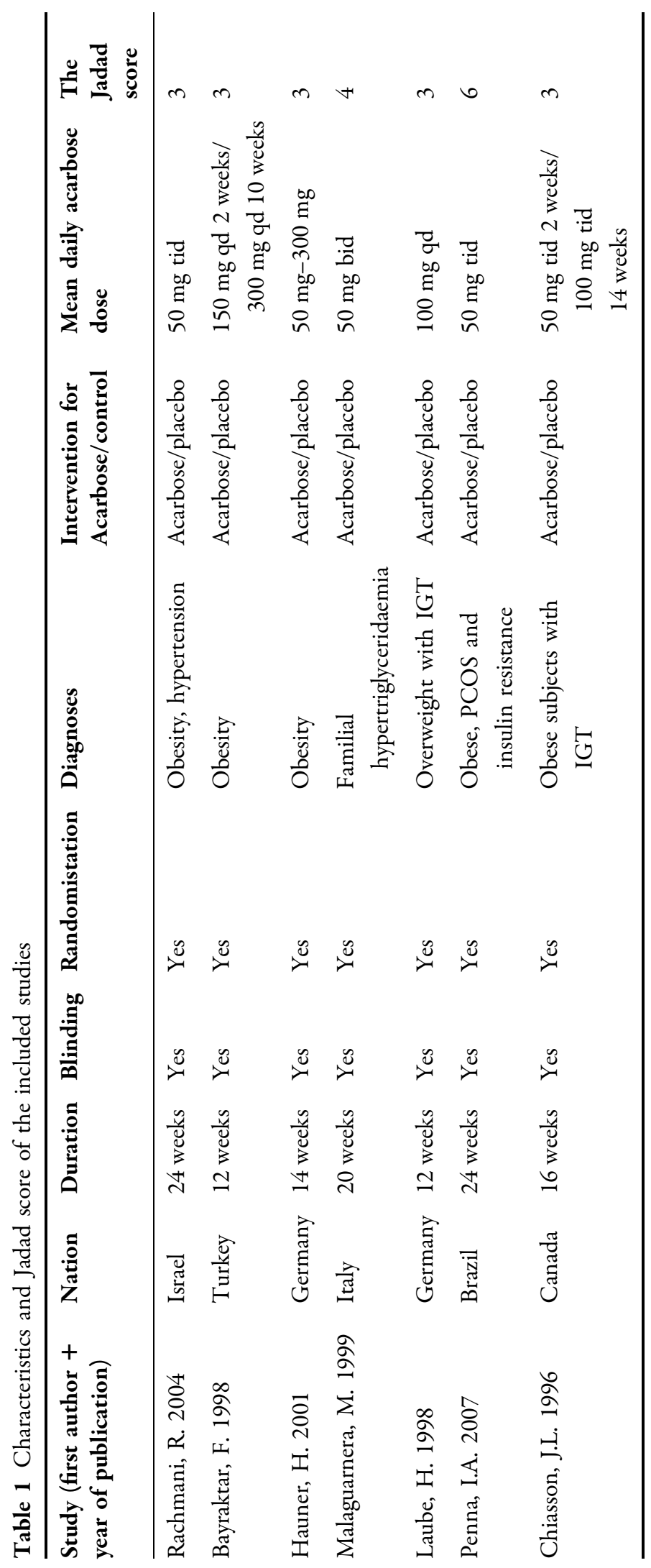

